\title{
Prioridades para investimentos em usinas elétricas
}

\author{
JOAQUIM FRANCISCO DE CARVALHO
}

\section{Introdução}

$\mathrm{P}$ ARA RECUPERAR o atraso nos investimentos do setor elétrico brasileiro, é necessário atribuir prioridades a projetos que possam entrar em operação em médio prazo. Claro está que os projetos prioritários não devem ser selecionados sob pressões comerciais, como às vezes acontece, mas sim com base em comparações entre as diversas opções disponíveis para a geração de eletricidade em larga escala, relativamente a aspectos tais como os impactos ambientais, a eventual exposição da população a riscos de acidentes e os custos, sobre os quais são estruturadas as tarifas a serem pagas pelos consumidores. É indispensável que se considerem também aspectos estratégicos, tais como os prazos previsíveis para a entrada em operação, as garantias de suprimento de combustíveis (gás, óleo etc.) e a existência de capacidade industrial em escala suficiente para o enriquecimento de urânio e fabricação dos elementos combustíveis, no caso de usinas nucleares.

Por força da extensão do assunto, este artigo restringe-se a uma comparação entre os custos previsíveis da energia gerada nos principais projetos atualmente considerados pelo governo, para entrar em operação em médio prazo, que são o da usina nuclear de Angra III e os das hidrelétricas de Belo Monte, no Rio Xingu, e Santo Antônio e Jirau, no Rio Madeira.

\section{Generalidades sobre os custos da energia elétrica em usinas nucleares e hidráulicas}

Os custos de produção de energia elétrica compõem-se de uma parte fixa, com base na qual o capital investido é remunerado e recuperado ao longo do prazo de depreciação contábil da usina geradora; e de uma parte administrável, composta pelas despesas necessárias ao funcionamento dessa usina. A parte fixa (capital investido) abrange as despesas incorridas na implantação da usina (estudos de viabilidade e de engenharia, equipamentos, canteiro da obra, construção, montagem e testes), e a parte administrável compreende as despesas de operação e manutenção, seguros, impostos, salários, encargos trabalhistas etc.

Os custos finais (soma das partes fixa e administrável) devem ser calculados de forma a permitir a estruturação de tarifas que assegurem uma remuneração que seja ao mesmo tempo atraente para o investidor e justa para os consumidores. Para isso - ou, por outras palavras, para evitar que os lucros do investidor 
(concessionário) sacrifiquem os consumidores -, a taxa interna de retorno (TIR) empregada no cálculo dos custos de geração deve ser estabelecida por meio de negociações entre o poder concedente e o investidor, nas quais entram critérios subjetivos tais como "atratividade" para o investidor e "razoabilidade" para os consumidores; daí o imperativo ético de que o processo seja absolutamente transparente. Na prática, com o setor elétrico submetido às forças do mercado, a taxa de retorno tende a acompanhar o custo da alternativa de investimento, isto é, o custo da oportunidade de se aplicar o capital em outros projetos (Bitu \& Born, 1993; Viscusi et al., 2000).

Em projetos capital intensive como são os do setor elétrico, o principal componente do custo corresponde à amortização do investimento (custo do capital). Os demais componentes (despesas de operação, seguros, taxas, salários etc.) incidem com intensidade menor, porém, na medida em que o projeto se aproxima do fim do prazo de depreciação contábil, a importância dessas despesas cresce em relação ao custo do capital.

A vida útil das hidrelétricas supera seu prazo de depreciação contábil, que é convencionalmente estabelecido em 30 anos. Assim, usinas já amortizadas continuam gerando energia a um custo que se reduz às despesas de operação e manutenção; seguros; salários e encargos trabalhistas. Existem no mundo hidrelétricas implantadas nos primeiros anos do século passado que continuam operando normalmente, o que constitui uma vantagem para a sociedade, que se beneficia do serviço sem o ônus de um novo investimento. A propósito, o custo de geração das usinas hidrelétricas brasileiras já amortizadas, que respondem por uma parte considerável da energia elétrica gerada no país, está em apenas cerca de US\$ 4/MWh (Campos Ferreira, 2002). Portanto, teria sido possível compor para o sistema elétrico brasileiro um mix tarifário que restituiria à sociedade as taxas e os impostos pagos ao longo de muitas décadas, para financiar a implantação desse parque. Com a desregulamentação do sistema elétrico e a privatização de grandes hidrelétricas que estavam prestes a chegar ao fim de seus prazos de depreciação contábil, tal composição tarifária tornou-se inviável.

Nas usinas hidrelétricas, o número de empregados das áreas operacional e administrativa fica em torno de 0,1 empregado por MW instalado. Nas usinas nucleares esse número é de, aproximadamente, 0,7 empregado por MW instalado. No Brasil, incluindo-se os encargos trabalhistas, as despesas salariais são da ordem de R \$ 48.000,00 por empregado/ano, nas usinas nucleares; e de R\$ $36.000,00$, nas hidrelétricas.

Os aproveitamentos hidrelétricos mais próximos dos pólos de consumo já estão sendo explorados, portanto não se pode esperar que a energia gerada em novas usinas tenha custos comparáveis aos das antigas, pois, entre outras coisas, deve-se acrescentar o custo da transmissão cuja incidência vai aumentando na medida em que os novos aproveitamentos localizem-se em regiões mais afastadas. 
O custo do combustível das usinas nucleares é composto pela soma dos custos de cada uma das etapas do ciclo do urânio, que vai da mineração até a fabricação dos elementos combustíveis. Nessa composição a etapa mais onerosa é a do enriquecimento, que entra com 36\%. A incidência do custo do urânio $\left(\mathrm{U}_{3} \mathrm{O}_{8}\right)$ fica em torno de $27 \%$.

O prazo de depreciação contábil das usinas nucleares coincide com a sua vida útil (cerca de 40 anos), após o que elas devem ser descontaminadas e descomissionadas.

As despesas de descomissionamento devem ser trazidas ao valor presente e incluídas nos custos de geração, a fim de constituir um fundo com recursos suficientes para aquelas despesas.

$\mathrm{Na}$ Grã-Bretanha, por exemplo, ${ }^{1}$ o governo atribuiu ao órgão público responsável pelo descomissionamento (Nuclear Decommissioning Authority) uma dotação orçamentária de $£ 2,47$ bilhões (US\$ 4,34 bilhões) para o exercício de $2007 / 2008$.

Outros componentes do custo da geração nuclear são o da administração dos rejeitos de baixa e média atividade, e o da deposição final dos rejeitos de alta atividade.

Tanto para as hidrelétricas como para as nucleares e as térmicas convencionais, os prêmios pagos às companhias de seguros são, em média, da ordem de $1 \%$ ao ano, sobre o capital investido.

\section{Custo de geração de Angra III}

Segundo a Eletronuclear (Barata, 2007), o orçamento para a conclusão de Angra III (atualizado em dezembro de 2007) é da ordem de R\$ 7,35 bilhões, sem incluir os juros durante a construção. A quantia já investida no projeto monta a R\$ 1,61 bilhão, sendo 65\% ( $\mathrm{R}$ \$ 1,05 bilhão) em despesas financeiras incorridas durante o tempo em que a obra ficou parada. Os restantes 35\% (R\$ 560 milhões) destinaram-se à aquisição dos principais componentes mecânicos do sistema nuclear de geração de vapor (vaso do reator, pressurizadores, geradores de vapor, bombas principais de refrigeração e suportes desses componentes). Foram também adquiridos alguns dos principais componentes do circuito secundário, tais como o grupo turbogerador, as bombas principais de água de alimentação e de condensado e, ainda, vários equipamentos de processo (estações de válvulas, trocadores de calor, vasos de pressão, tubulações etc.). Esses componentes estão armazenados no próprio sítio da usina e nas instalações da Nuclebrás Equipamentos Pesados S. A. (Nuclep), em Itaguaí (RJ).

Depreende-se daí que o verdadeiro custo de Angra III será de R\$ 7,91 bilhões (isto é, R\$ 7,35 bilhões + R\$ 560 milhões), sem os juros durante a construção. Nos cálculos apresentados na Tabela 1 , as despesas já feitas foram lançadas a fundo perdido, pois o governo assim já decidiu. Por conseguinte, o valor calculado (R\$ 180,00/MWh) é, na realidade, um custo subsidiado, que, 
evidentemente, não deverá prevalecer para futuras usinas do mesmo tipo que, porventura, venham a ser implantadas.

Nesses cálculos, admitiu-se que a TIR será de 10\% ao ano e que Angra III operará com o fator de capacidade esperado pela Eletronuclear (87\%), valor muito otimista, comparado, por exemplo, ao do parque nuclear francês, que não chega a $78 \%{ }^{2}$

Admitiu-se, ainda, que o BNDES financiará $70 \%$ do orçamento para a conclusão da obra, a juros de 7,5\% ao ano (TJLP + 1\%), entrando os 30\% restantes como equity, a $8 \%$ ao ano, durante a construção.

De acordo com a Eletronuclear, a implantação de Angra III levará 66 meses (construção civil, montagem eletromecânica, comissionamento dos sistemas e testes pré-operacionais), começando com os trabalhos de concretagem da laje de fundação do edifício do reator e terminando com os testes de potência da usina.

Tabela 1 - Custo de geração de Angra III

\begin{tabular}{|c|c|}
\hline Potência elétrica instalada & $1.345 \mathrm{MW}$ \\
\hline Custo da usina, $s /$ juros durante a construção - $\mathrm{C}_{1}$ (em mil reais) & 7.350 .000 \\
\hline Despesas do concessionário ( $8 \%$ de $\mathrm{C}_{1}$ ) & 588.000 \\
\hline Custo direto $-\mathrm{C}_{2}$ & 7.938 .000 \\
\hline $\begin{array}{l}\text { JDC ( } 6 \text { anos, } 7,5 \% \text { a.a. sobre } 70 \% \text { de } \mathrm{C}_{2}+8 \% \text { a.a } \\
\text { sobre } 30 \% \text { de } \mathrm{C}_{2} \text { ) }\end{array}$ & 4.410 .491 \\
\hline Capital necessário para o investimento $-\mathrm{C}_{3}$ & 12.348 .491 \\
\hline \multicolumn{2}{|c|}{$\begin{array}{l}\text { CUSTOS ANUAIS (em mil reais) } \\
\text { Depreciação contábil em } 40 \text { anos, com TIR }=10 \% \text { a.a. } \rightarrow \mathrm{FRC}=0,1022\end{array}$} \\
\hline Anuidade para a recuperação do capital (em mil reais) & 1.262 .015 \\
\hline Seguros ( $1 \%$ de $\mathrm{C}_{3}$, ao ano) & 123.485 \\
\hline Manutenção & 220.000 \\
\hline Salários + encargos trabalhistas + administração & 43.000 \\
\hline Total dos custos anuais & 1.648 .500 \\
\hline \multicolumn{2}{|l|}{ CUSTO DE GERAÇÃO (em reais/MWh) } \\
\hline Incidência dos custos anuais (fator de capacidade $=87 \%$ ) & $160 / \mathrm{MWh}$ \\
\hline Combustível & आमाणाण : K \\
\hline 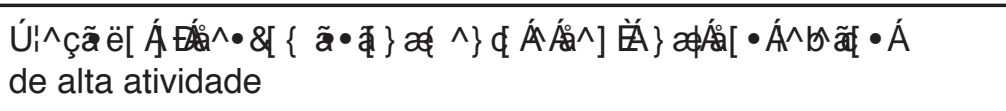 & $3 / \mathrm{MWh}$ \\
\hline Soma $\Rightarrow$ custo de geração de Angra III & $\mathrm{R} \$ 180 / \mathrm{MWh}$ \\
\hline
\end{tabular}


Para comparação, cabe notar que, internacionalmente, o prazo de construção de usinas nucleares é, em média, de cinco a sete anos; a taxa de juros durante a construção (JDC) é de $8 \%$ a $10 \%$ ao ano sobre $50 \%$ do investimento (os outros $50 \%$ constituem capital acionário); a TIR é de $10 \%$ a $15 \%$ ao ano, e o prazo de amortização é de 40 anos, coincidindo com a vida útil da unidade, ao cabo da qual deve ela ser descomissionada.

O descomissionamento implica futuros investimentos entre US\$ $350 \mathrm{e}$ US\$ 500 por $\mathrm{kW}$ elétrico instalado. ${ }^{3}$

Estima-se que, no Brasil, as despesas de descomissionamento, somadas aos custos da administração dos rejeitos de baixa e média atividade e ao que será gasto futuramente, na deposição final dos rejeitos de alta atividade, incidam com cerca de R\$ 3/MWh na tarifa de geração, ao longo da vida útil da usina.

Assumiu-se, como faz a Eletronuclear, que o custo do combustível ficará estacionado em apenas R\$17,6/MWh, ou seja, o mesmo de Angra II. Aqui é importante ressalvar que, desde o final da década de 1980 até meados de 2003, a cotação do urânio $\left(\mathrm{U}_{3} \mathrm{O}_{8}\right)$ no mercado internacional permaneceu estável, em torno de US\$ 18 a US\$ 20 por $\mathrm{kg}$. A partir daí os preços subiram rapidamente, atingindo US\$ 200 por kg, em 2006. Houve, portanto, uma valorização da ordem de $1.000 \%$ em apenas três anos (WEC, 2007).

Embora na formação do custo do combustível o preço do urânio tenha uma incidência de apenas $27 \%$ em relação às demais etapas do ciclo, é possível que a crescente demanda mundial venha a induzir uma valorização que faça desse preço um fator de incerteza. Essa eventualidade deve ser considerada na análise dos aspectos estratégicos do projeto de Angra III.

\section{Custo de geração das usinas hidrelétricas de Belo Monte, Santo Antônio e Jirau}

A usina de Belo Monte representará o primeiro passo para o aproveitamento do potencial hidrelétrico do Rio Xingu. Na região indicada para o projeto (Volta Grande do Xingu), o rio corre num canyon que faz uma curva e retorna no sentido oposto, desenhando uma figura em forma de ferradura, quase fechada. $\mathrm{O}$ desnível entre a entrada e a saída dessa curva é de 90 metros, e, na saída, o fluxo turbinável é de, aproximadamente, $13.900 \mathrm{~m}^{3} / \mathrm{seg}$. O anteprojeto inicial da obra previa a construção de uma barragem na saída do canyon, para alimentar uma casa de força com a capacidade de $11.000 \mathrm{MW}$ (20 máquinas de $550 \mathrm{MW}$ ). Essa configuração apresentava os inconvenientes de alagar uma ilha de onde teriam que ser removidos cerca de 400 indígenas, e de inundar toda a área abrangida pela concavidade da curva em forma de ferradura, descrita pelo canyon (aproximadamente $1.225 \mathrm{~km}^{2}$ ), numa região de biodiversidade extremamente rica. Esses inconvenientes provocaram rumorosos protestos de grupos ambientalistas.

Preparou-se então um projeto alternativo que não alagará a ilha nem a área circunscrita pela curva, preservando-se dessa forma a biodiversidade. A idéia básica desse projeto é construir, antes da entrada do canyon, uma barra- 
gem menor, formando, a montante, um lago de $420 \mathrm{~km}^{2}$, área que corresponde a apenas o dobro da expansão normal do rio em seu leito, nas épocas chuvosas. Uma pequena parte da água aí acumulada alimentará uma casa de força com sete máquinas de $25,9 \mathrm{MW}$ (capacidade total $\approx 181 \mathrm{MW}$ ), e a maior parte descerá por um sistema de canais, diques e penstocks, diretamente até uma casa de força construída na saída do canyon, situada 90 metros abaixo, para alimentar 20 máquinas de $550 \mathrm{MW}$, ou seja, $11.000 \mathrm{MW}$. Teremos assim, no total, uma capacidade instalada de $11.181 \mathrm{MW}$.

Nessa configuração, o custo do investimento em Belo Monte será de, aproximadamente, R \$ 7,5 bilhões, já incluídas as despesas de preparação do sítio e de mitigação dos impactos ambientais e sem os juros durante a construção.

Na Tabela 2 apresenta-se o cálculo do custo de geração de Belo Monte, feito com base em condições financeiras semelhantes às de Angra III.

Tabela 2 - Custo de geração de Belo Monte

\begin{tabular}{|c|c|}
\hline Potência elétrica instalada & $11.181 \mathrm{MW}$ \\
\hline Custo da usina - $\mathrm{C}_{1}$ (em mil reais) & 7.500 .000 \\
\hline Despesas do concessionário $\left(10 \%\right.$ de $\left.\mathrm{C}_{1}\right)$ & 750.000 \\
\hline Custo direto, sem juros durante a construção - $C_{2}$ & 8.250 .000 \\
\hline JDC (5 anos, $7,5 \%$ a.a. sobre $70 \%$ de $\mathrm{C}_{2}+8 \%$ a. a sobre $30 \%$ de $\mathrm{C}_{2}$ ) & 3.677 .346 \\
\hline Capital necessário para o investimento $-\mathrm{C}_{3}$ & 11.927 .346 \\
\hline \multicolumn{2}{|l|}{$\begin{array}{c}\text { CUSTOS ANUAIS (em mil reais) } \\
\text { Depreciação em } 30 \text { anos, com TIR }=10 \% \text { a.a. } \rightarrow \text { FRC }=0,1061 \text { ) }\end{array}$} \\
\hline Anuidade para a recuperação do capital & 1.265 .491 \\
\hline Seguros ( $1 \%$ de $\mathrm{C}_{3}$, ao ano) & 119.274 \\
\hline Manutenção ( $1 \%$ de $C_{1}$, ao ano) & 75.000 \\
\hline Salários + encargos trabalhistas + administração & 40.252 \\
\hline Total dos custos anuais & 1.500 .017 \\
\hline \multicolumn{2}{|l|}{ CUSTO DE GERAÇÃO (em reais/MWh) } \\
\hline Incidência dos custos anuais (fator de capacidade = $40 \%$ ) & 39 \\
\hline$\Rightarrow$ Custo de geração de Belo Monte & $\mathrm{R} \$ 39 / \mathrm{MWh}$ \\
\hline
\end{tabular}

Em razão da irregularidade da vazão do Rio Xingu, o fator de capacidade da usina será de apenas $40 \%$, portanto sua potência firme ficará em $4.472 \mathrm{MW}$, valor que poderá melhorar, à medida que forem sendo implantados outros aproveitamentos já inventariados a montante de Belo Monte e que se interliguem 
os sistemas elétricos das regiões Norte e Nordeste. Estudos da Eletronorte estimam em $32.000 \mathrm{~m}^{3}$ /segundo a vazão regularizada do Xingu, fluxo que permitirá ainda a instalação de projetos de menor porte, perfazendo uma capacidade da ordem de 5.000 MW, a montante de Belo Monte.

O cronograma preliminar colocava o início da obra em abril de 2010, com a primeira máquina entrando em testes em junho de 2014.

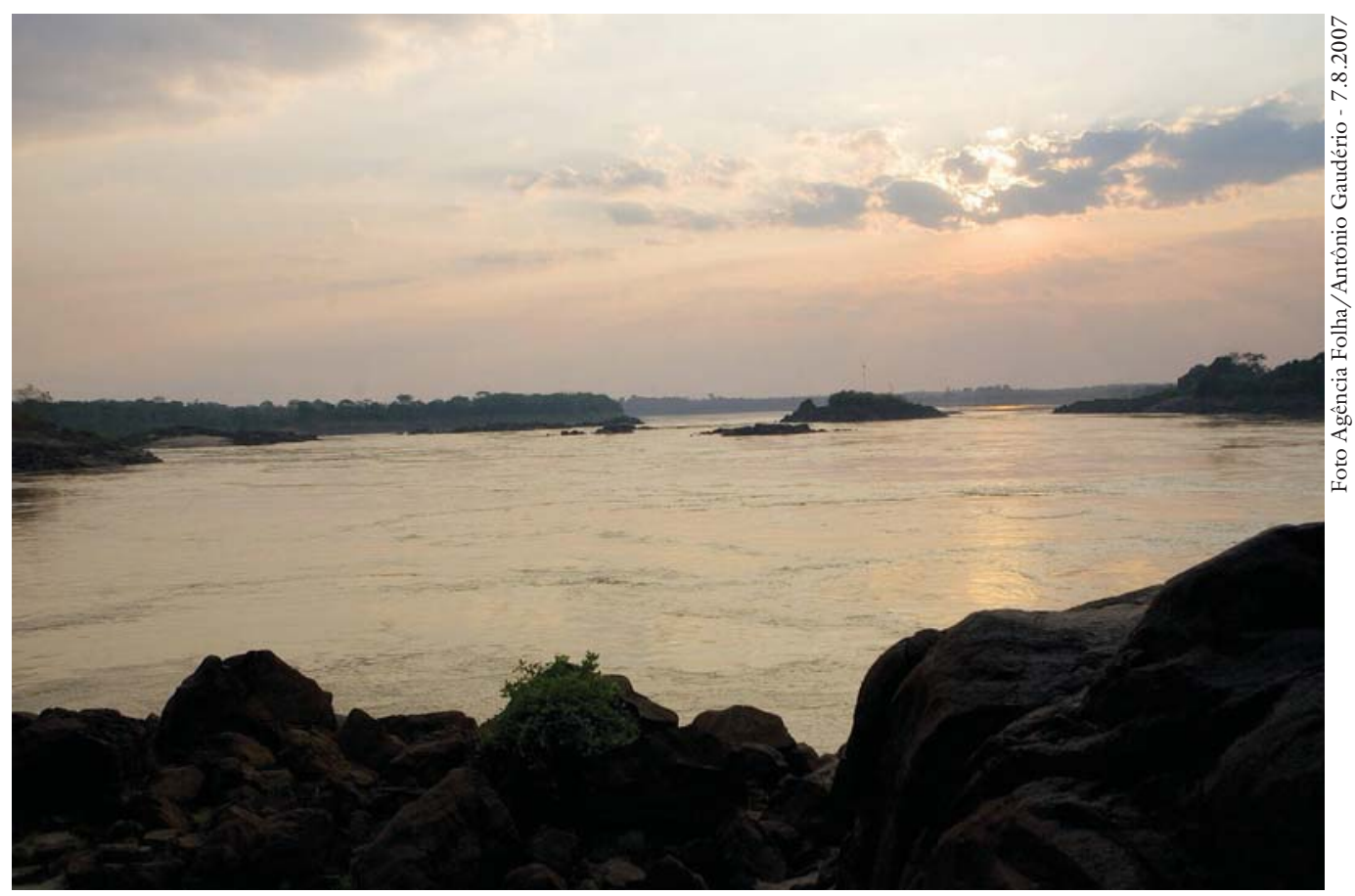

Corredeiras do Rio Madeira, conbecidas como Cachoeira de Santo Antônio, onde será construida a usina hidrelétrica de Santo Antônio, em Porto Velho (RO).

As hidrelétricas de Santo Antônio e Jirau, com potências instaladas de 3.150 MW e 3.300 MW, respectivamente, situam-se no Rio Madeira, Estado de Rondônia, município de Porto Velho. As usinas serão compostas por barragens a fio d'água, casas de força, vertedouros e turbinas de tipo bulbo. O aspecto inovador do projeto é o emprego de turbinas desse tipo em grandes hidrelétricas. Graças a isso, ambos os aproveitamentos serão de baixa queda, com reservatórios que inundarão áreas de $271 \mathrm{~km}^{2}$ (Santo Antônio) e $258 \mathrm{~km}^{2}$ (Jirau), pequenas para hidrelétricas desse porte.

O plano original previa ainda algumas eclusas, para formar uma hidrovia ligando o interior da Bolívia ao Rio Amazonas, numa extensão de aproximadamente quatro mil quilômetros.

O orçamento preliminar, feito por Furnas em colaboração com uma empreiteira, colocava o custo da implantação das duas usinas em R 25 bilhões, incluindo os juros durante a construção e as despesas do concessionário na ins- 
talação dos canteiros das obras e na mitigação dos impactos ambientais, valor que parece muito elevado, pois, dadas as características dos dois sítios, o custo unitário dessas usinas não deverá exceder $\mathrm{R} \$ 2.700 / \mathrm{kW}$ instalado, de modo que o investimento total em ambas não deveria passar de algo em torno de R $\$ 17,5$ bilhões. A Tabela 3 apresenta, com base nesse valor e em condições financeiras semelhantes às de Angra III, o custo de geração de Santo Antônio e Jirau.

Tabela 3 - Custo de geração de Santo Antônio e Jirau

\begin{tabular}{|l|r|}
\hline Potência elétrica total das duas usinas & $6.450 \mathrm{MW}$ \\
\hline Capital necessário para o investimento (em mil reais) & 17.500 .000 \\
\hline \multicolumn{2}{|c|}{ CUSTOS ANUAIS (em mil reais) } \\
\hline \multicolumn{2}{|c|}{ Depreciação contábil em 30 anos com TIR = 10\% a.a $\rightarrow$ FRC = 0,106) } \\
\hline Anuidade para a recuperação do capital (em mil reais) & 1.855 .000 \\
\hline Seguros & 164.000 \\
\hline Manutenção & 147.000 \\
\hline Salários + encargos trabalhistas + administração & 23.220 \\
\hline Total dos custos anuais & 2.189 .220 \\
\hline \multicolumn{2}{|c|}{ CUSTOS DE GERAÇÃO (em reais/MWh) } \\
\hline Incidência dos custos anuais (com fator de capacidade de 50\%) \\
\hline$\Rightarrow$ Custo de geração do complexo do Rio Madeira \\
\hline
\end{tabular}

Pelo cronograma preliminar - que está sendo reformulado -, o início da obra de Santo Antônio estava previsto para outubro de 2008, e a primeira máquina deveria entrar em testes em meados de 2012. A de Jirau começaria em outubro de 2009, e a primeira turbina seria testada em 2013.

\section{Considerações finais e conclusões}

A conexão de Belo Monte à rede básica implicará um custo de transmissão de, aproximadamente, R\$10/MWh, de modo que sua energia deverá chegar ao sistema interligado por algo em torno de R\$ 49/MWh. Para as usinas do Rio Madeira, a transmissão custará cerca de R $20 / \mathrm{MWh}$; portanto, a energia chegará ao sistema por R\$97/MWh, aproximadamente.

A comparação (Tabela 4) entre os custos da energia das usinas examinadas neste artigo aponta na direção do projeto de Belo Monte para, em princípio, receber tratamento prioritário no processo alocação de recursos - seja do orçamento da União, seja de bancos oficiais - para o início das obras. Uma eventual decisão de se terminar a obra de Angra III apenas para justificar o investimento já realizado poderia revelar-se equivocada, pois, em um ano de operação, Angra III produziria 10.943.913 MWh, a um custo de R\$ 1,97 bilhão de reais. Em um 
ano, Belo Monte produziria quase quatro vezes mais energia, praticamente pelo mesmo custo.

Para gerar a mesma quantidade de energia que Angra III geraria em um ano, a um custo de R\$ 1,97 bilhão, Belo Monte gastaria apenas R \$ 536 milhões de reais. A economia seria, portanto, da ordem de R 1,43 bilhão, por ano.

Tabela 4 - Custo da energia, geração anual e data de início de operação

\begin{tabular}{|l|r|c|c|}
\hline PROJETO & $\begin{array}{c}\text { Custo da } \\
\text { energia }\end{array}$ & $\begin{array}{c}\text { Produção } \\
\text { anual }\end{array}$ & $\begin{array}{c}\text { Início de } \\
\text { operação }\end{array}$ \\
\hline Angra III (c/ subsídios) & $\mathrm{R} \$ 180 / \mathrm{MWh}$ & $10.943 .913 \mathrm{MWh}$ & $2015 / 2016$ \\
\hline Belo Monte & $\mathrm{R} \$ 49 / \mathrm{MWh}$ & $39.205 .058 \mathrm{MWh}$ & $2014 / 2015$ \\
\hline Complexo do Madeira & $\mathrm{R} \$ 97 / \mathrm{MWh}$ & $28.270 .350 \mathrm{MWh}$ & $2013 / 2014$ \\
\hline
\end{tabular}

Quanto à tecnologia, cumpre observar que a finalidade de usinas nucleares é gerar energia elétrica, o que não requer know-how de projeto e construção de usinas nucleares, mas apenas experiência em operação e manutenção. A Eletronuclear já dispõe de quadros altamente qualificados, que adquiriram muita experiência na operação e manutenção de Angra I e Angra II. Esses quadros renovam-se continuamente com os mais jovens que ingressam na empresa, sendo treinados e absorvendo experiência dos que estão próximos da aposentadoria. Não é necessário construir Angra III para preservar essa experiência. E construíla com o objetivo de desenvolver tecnologia de projeto e construção de usinas nucleares equivaleria a comprar um Airbus A380, que pode ser muito bem pilotado por pilotos formados no Brasil, mas que não têm - nem poderiam ter - a incumbência de projetar e construir aviões. De fato, as companhias aéreas brasileiras sempre compraram e operaram aviões modernos, no entanto a indústria aeronáutica brasileira só se desenvolveu com a criação do Instituto Tecnológico da Aeronáutica, que estimulou a criação da Embraer e as empresas que estão em sua cadeia produtiva.

Analogamente, a capacidade brasileira para fazer o projeto básico, desenvolver os materiais, desenhar os sistemas e construir uma usina nuclear, só será adquirida quando o governo - em vez de comprar projetos feitos no exterior, como o de Angra III - entregar a institutos brasileiros dedicados à pesquisa tecnológica a responsabilidade de desenvolver e construir um protótipo e, em seguida, escalá-lo para produção industrial. Entre esses institutos, destacam-se o Instituto de Pesquisas Energéticas e Nucleares de São Paulo (Ipen), a Coordenação dos Programas de Pós-Graduação em Engenharia da UFRJ (Coppe), o Centro Tecnológico da Marinha (CTMSP) e o Instituto de Pesquisas Tecnológicas de São Paulo (IPT), entre outros.

Um programa destinado a desenvolver um protótipo de reator a ser escalado e, posteriormente, fabricado comercialmente pela indústria local e montado 
por firmas de engenharia brasileiras poderia ser financiado com recursos provenientes da diferença entre os custos de geração de Angra III e Belo Monte.

Quanto à unidade de enriquecimento de urânio, em Rezende (RJ), nada impede que sua implantação seja completada e que o governo compre parte de sua produção, para acumular um estoque estratégico de urânio enriquecido a $3 \%$, que é impróprio para fins bélicos, porém importante para ser usado futuramente, em usinas nucleares projetadas no Brasil, caso ainda não se tenha desenvolvido alternativa mais interessante para ser empregada quando o potencial hidrelétrico estiver plenamente aproveitado.

\section{Notas}

1 Nuclear Engineering International, 5 June 2007.

2 Agence pour l'énergie nucléaire de l'OCDE (http://www.nea.fr).

3 IEA Energy Technology Essentials - Nuclear Power - march 2007.

\section{Referências bibliográficas}

BITU, R.; BORN, P. Tarifas de energia elétrica - Aspectos conceituais e metodológicos. São Paulo: MM Editora, 1993.

BARATA, R. Intervenção em seminário promovido em 12 de dezembro de 2007 , no IEA/USP, baseada no relatório ETN nº BN/3/0256/040001, revisão 3 ${ }^{\underline{a}}$, de 2007, da Eletronuclear.

CAMPOS FERREIRA, O. O sistema elétrico brasileiro. Economia es Energia, n.3, maio/junho, 2002.

VISCUSI, W. K. et al. Economics of Regulation and Antitrust. Cambridge: The MIT Press, 2000.

WORLD ENERGY COUNCIL (WEC). The Role of Nuclear Energy in Europe 2007.

RESUMO - Por motivos não abordados neste artigo, projetos importantes sofreram atrasos em seus cronogramas, aumentando o risco de que, em futuro próximo, o Brasil venha a enfrentar uma crise de abastecimento de energia elétrica, com sérios impactos sobre a produção industrial e a qualidade de vida da população. Entre os principais projetos de geração em estudo no Ministério de Minas e Energia para entrar em operação a tempo de reduzir esse risco estão os de Angra III e de algumas hidrelétricas amazônicas, o que tem suscitado dúvidas e provocado debates pela imprensa, particularmente sobre os custos da eletricidade gerada nessas usinas. Procuramos, neste artigo, esclarecer algumas dessas dúvidas.

PALAVRAS-CHAVE: Usinas nucleares, Custos de geração elétrica.

ABSTRACT - Due to reasons out of the scope of this article, important investments in the electric sector were delayed, increasing the risk of power shortages in Brazil in the near 
future, with serious impacts on industrial production and quality of life. Among the projects being studied by the Ministry of Energy to be operative in time to reduce that risk are the Angra III nuclear power plant and some hidro power plants in Northern Brazil, what raises doubts and provokes debates in the press, chiefly about the costs of the energy produced. In this article we try clear up some of these doubts.

KEYWORDS: Nuclear power plants, Power generation costs.

Joaquim Francisco de Carvalho pertence ao Programa Interunidades de Pós-Graduação em Energia da Universidade de São Paulo. @ - jfdc35@uol.com.br

Recebido em 23.1.2008 e aceito em 28.5.2008. 